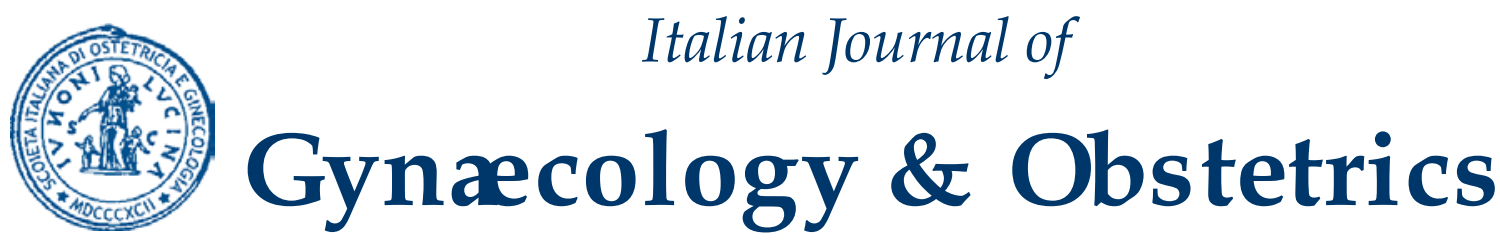

March 2020 - Vol. 32 - N. 1 - Quarterly - ISSN 2385 - 0868

\title{
Electrochemotherapy in vulvar cancer: a systematic review
}

\author{
C. Certelli1 1 , G. Garganese1,5, S. Fragomeni1, L. Tagliaferri², I. Paris ${ }^{1}$, M. A. Gambacorta 3 , \\ G. Scambia ${ }^{4}$, G. Corrado ${ }^{1}$
}

1Dipartimento Scienze della Salute della Donna, del Bambino, e di Sanità Pubblica, Ginecologia Oncologica, Fondazione Policlinico Universitario A. Gemelli IRCCS, Rome, Italy

2Dipartimento di Diagnostica per immagini, Radioterapia Oncologica ed Ematologia, Gemelli ART (Advanced Radiation Therapy), Interventional Oncology Center (IOC) Fondazione Policlinico Universitario A. Gemelli IRCCS, Rome, Italy

3Dipartimento di Diagnostica per immagini, Radioterapia Oncologica ed Ematologia, Gemelli ART (Advanced Radiation Therapy), Interventional Oncology Center (IOC) Fondazione Policlinico Universitario A. Gemelli IRCCS, Università Cattolica del Sacro Cuore, Rome, Italy ${ }^{4}$ Dipartimento Scienze della Salute della Donna, del Bambino, e di Sanità Pubblica, Ginecologia Oncologica, Fondazione Policlinico Universitario A. Gemelli IRCCS, Università Cattolica del Sacro Cuore, Rome, Italy ${ }^{5}$ Gynecology and Breast Care Center, Mater Olbia Hospital, Olbia, Italy

\section{ABSTRACT}

There are some problems about the optimal treatment modality of vulvar cancer (VC): unfeasible surgery in elderly women with several comorbidities and the absence of treatments applicable in recurrent disease. For these reasons, Electrochemotherapy (ECT) may have an important role in the management of these patients. The aim of this systematic review is to evaluate ECT in VC in terms of clinical response, adverse events and quality of life (QoL). We conducted a search on the electronic database PubMed/MEDLINE. All the studies in English language published from 2006 and August 2019 were considered eligible. The 4 studies included in the systematic review reported an overall objective response rate (complete and partial response) was $74.3 \%$. No treatment-related serious adverse events were reported in any of the studies. An improvement in the QoL was reported. In conclusion, ECT is an easy, quick to perform, less invasive and repeatable procedure, which have shown a positive clinical response, a reduction in symptoms and an improvement in QoL. Since the survival for advanced and metastatic diseases has been, fortunately, increased, it is also important to focus our efforts on the QoL and on the local control of the disease.

Corresponding Author: Camilla Certelli

certelli.camilla@gmail.com

Copyright 2020

DOI: $10.36129 /$ jog.32.01.03

\section{SOMMARIO}

Alcune delle problematiche sul trattamento ottimale del carcinoma vulvare $(\mathrm{CV})$ sono rappresentate dalle controindicazioni all'esecuzione di un intervento chirurgico nelle donne anziane con comorbidità e dall'assenza di ulteriori trattamenti somministrabili nella malattia recidivante. Per questi motivi, l'elettrochemioterapia (ECT) potrebbe avere un ruolo importante nella gestione di queste pazienti. Lo scopo di questa review sistematica è quello di valutare $\mathrm{l}^{\prime} \mathrm{ECT}$ in termini di risposta clinica, eventi avversi e qualità di vita (QoL). Tramite una ricerca su PubMed/MEDLINE, tutti gli studi in lingua inglese pubblicati dal 2006 all'agosto 2019 sono stati presi in considerazione. I 4 studi inclusi nella review sistematica hanno riportato una risposta clinica complessiva (completa e parziale) del $74.3 \%$. Sono stati riportati, inoltre, l'assenza di gravi eventi avversi e un miglioramento della QoL. In conclusione, l'ECT è una procedura semplice, veloce, poco invasiva e ripetibile, che ha mostrato una risposta clinica positiva, una riduzione della sintomatologia ed un miglioramento della QoL. In un contesto in cui, fortunatamente, la sopravvivenza per le malattie avanzate e/o metastatiche sta aumentando, è importante concentrare i nostri sforzi anche sulla QoL e sul controllo locale di malattia.

Key words: electrochemotherapy; vulvar cancer; palliative therapies 


\section{INTRODUCTION}

Electrochemotherapy (ECT) combines electroporation and chemotherapeutic drugs in order to destroy or reduce in size different kinds of lesions. The electroporation improves drugs delivery by increasing the cell membrane permeability and makes chemotherapy more effective (1). There are three mechanisms of action of ECT (2): first, the cytotoxic effect of chemotherapy; second, an anti-vascular effect with a vasoconstriction phase followed by vascular disruption $(3,4)$; third, an immune stimulation $(5,6)$. The applications of ECT have been extended in recent years. ECT has been used in the treatment of metastatic melanoma in conjunction with standard chemotherapy in order to obtain a better local control of the disease $(7,8)$. Two recent multicentric studies reported $71 \%$ of positive response to the ECT treatment in breast cancer patients $(9$, 10). In head and neck cancers, ECT may be a valid less invasive option to preserve physiological functions (11). Furthermore, ECT showed positive results in non-melanoma skin cancers and soft tissues sarcomas and even in non-cancer skin lesions (2). More recently, promising results have been reported in vulvar cancer treatment. Vulvar cancer (VC) accounts for $5 \%$ of all gynaecologic malignancies (12) and there are some problems about the optimal treatment modality. Indeed, radical surgery often requires the need for plastic reconstruction, by different techniques $(13,14)$, and frequently involves a high post-operative burden (15). On the one hand, since vulvar cancer mainly affects elderly women, comorbidities often make surgery unfeasible, whereas on the other hand, even when surgery, chemotherapy and/or radiotherapy are applicable, in the different settings up to the palliative care $(16,17,18)$, recurrences are not rare and to provide additional care remains a real challenge. For these reasons, ECT may have an important role in the management of these patients. The aim of this systematic review is to evaluate ECT in VC in terms of clinical response, adverse events and quality of life (QoL).

\section{MATERIALS AND METHODS}

The Preferred Reporting Items for Systematic Reviews and Meta-Analyses statement (PRIS-
MA) was used as a guide for this systematic review (19).

The Population, Intervention, Comparator and Outcomes (PICO) framework was used to formulate a search question in the following way: $\mathrm{P}$ : vulvar cancer; I: electrochemotherapy; O: clinical response. The " $\mathrm{C}$ " was not included because of the absence of a comparator. Indeed, ECT is emerging in more recent years and it is used as a palliative treatment in the majority of the cases. For this reason, comparing ECT with other less effective or none treatment would be unethical. Although the first objective of this systematic review was the evaluation of the clinical response, we added two secondary endpoints of our research: the evaluation of the adverse events and the QoL. We conducted a search on the electronic database PubMed/MEDLINE, by using the following terms: "electrochemotherapy" OR "ECT" AND "vulvar cancer". All the studies in English language published from the publication of the Standard Operating Procedures in 2006 (20) and August 2019 were considered eligible. The inclusion criteria were: diagnosis of VC, studies in which at least one of the three endpoints (clinical response, adverse events and QoL) was evaluated, studies in which the ECT was used as adjuvant or exclusive treatment. Abstracts, communications, comments, reviews and non-English language studies were excluded. Since this study is a systematic review of the literature based on previous published articles, no ethical approval or patient consent are required.

\section{RESULTS}

The search yielded a total of 8 studies after duplicates were removed (figure 1). We excluded 4 studies because of the following reasons: published before 2006, reviews or ECT was not used as exclusive or adjuvant treatment. Thus, 4 studies were included in the systematic review. All the studies included were prospective and the total number of patients was 105. Patients' and studies characteristics are shown in table I. The median age ranged from 68 to 85 years. Although the most common histology of VC was squamous cell carcinoma, there were two studies that included Paget diseases and one vulvar melanoma. Up to $40 \%$ of the patients in each 
Table I. Patients' and studies characteristics.

\begin{tabular}{|c|c|c|c|c|c|c|c|c|c|c|}
\hline \multirow{2}{*}{ Author } & \multirow{2}{*}{$\begin{array}{l}\text { Type of } \\
\text { study }\end{array}$} & \multirow{2}{*}{ Patients } & \multirow{2}{*}{ Age } & \multicolumn{4}{|c|}{ FIGO stage } & \multirow{2}{*}{ Histology } & \multirow{2}{*}{$\begin{array}{l}\text { Previous } \\
\text { treatments }\end{array}$} & \multirow{2}{*}{$\begin{array}{c}\text { Multiple } \\
\text { lesions }\end{array}$} \\
\hline & & & & I & II & III & IV & & & \\
\hline $\begin{array}{l}\text { Perrone } \\
\text { et al. } \\
2013 \\
{[23]}\end{array}$ & prospective & 9 & $\begin{array}{c}84 \pm \\
3.9\end{array}$ & $\begin{array}{c}2 \\
(22 \%)\end{array}$ & $\begin{array}{c}3 \\
(33 \%)\end{array}$ & $4(45 \%)$ & 0 & SCC & 8 (88.9\%) & $2(25 \%)$ \\
\hline $\begin{array}{l}\text { Perrone } \\
\text { et al. } \\
2015 \\
{[21]}\end{array}$ & prospective & 25 & $\begin{array}{c}85 \\
(66-96)\end{array}$ & $\begin{array}{c}13 \\
(52 \%)\end{array}$ & $\begin{array}{c}8 \\
(32 \%)\end{array}$ & $3(12 \%)$ & $1(4 \%)$ & SCC & $21(84 \%)$ & $8(32 \%)$ \\
\hline $\begin{array}{l}\text { Perrone } \\
\text { et al. } \\
2016 \\
{[24]}\end{array}$ & prospective & 10 & $\begin{array}{c}68 \\
(59-84)\end{array}$ & $\begin{array}{c}4 \\
(40 \%)\end{array}$ & $\begin{array}{c}4 \\
(40 \%)\end{array}$ & $1(10 \%)$ & 0 & $\begin{array}{l}\text { SCC } \\
1 \text { PD }\end{array}$ & $8(80 \%)$ & $4(40 \%)$ \\
\hline $\begin{array}{l}\text { Perrone } \\
\text { et al. } \\
2019 \\
{[22]}\end{array}$ & prospective & 61 & $\begin{array}{c}79 \\
(39-85)\end{array}$ & $\begin{array}{c}24 \\
(39 \%)\end{array}$ & $\begin{array}{c}3 \\
(4.9 \%)\end{array}$ & $\begin{array}{c}7 \\
(11.5 \%)\end{array}$ & $\begin{array}{c}2 \\
(3.3 \%)\end{array}$ & $\begin{array}{c}\text { SCC } \\
3 \text { PD } \\
1 \\
\text { Melanoma }\end{array}$ & 45 (73.8\%) & $24(39.3 \%)$ \\
\hline
\end{tabular}

Data are shown as median (range) or mean \pm SD and $n(\%)$. SCC: squamous cell carcinoma. PD: Paget Disease

study showed multiple lesions at the first pretreatment examination. The primary tumour FIGO stage was I in the majority of the patients $(41 \%)$, whereas only 3 patients were in FIGO stage IV. The majority of the patients $(78 \%)$ underwent previous treatments before ECT, which were surgery in most of the cases with or without adjuvant therapies such as chemotherapy and/or radiotherapy. Data about ECT administration and clinical response are shown in table II. All the studies used intravenous Bleomycin as chemotherapeutic drug. In most of the patients general anaesthesia was used and the duration of the procedure was 20-28 $\mathrm{min}$. The median hospital stays after ECT ranged from 1 to 3 days. For the response evaluation, two studies used the World Health Organization (WHO) criteria, whereas the other two studies used the Response Evaluation Criteria in Solid Tumours (RECIST) and the time of the response evaluation was in most of the studies 1 month. As regards the response rate, the 4 studies reported the following results: $49(46.7 \%)$ complete response (CR), 29 (27.6\%) partial response (PR), 12 $(11.4 \%)$ stable disease (SD) and 8 (7.6\%) progressive disease (PD). The overall objective response rate (CR and PR) was $74.3 \%$. No differences in the clinical response emerged between previously treated and non-treated patients (21) and, in the same way, no variations in the response rate emerged according to the number or diameter of the lesions $(21,22)$.

Furthermore, Perrone et al. showed that age, BMI, FIGO stage, site and histology did not influence the response to the treatment (22).

No treatment-related serious adverse events were reported in any of the studies. Some studies reported minor local side effects such as minimal blood loss, oedema, erythema, hyperpigmentation, skin ulceration and mild pain (table II) $(21,22,23)$.

Only three studies evaluated the QoL and all of them reported a significant QoL improvement after treatment $(23,24)$.

In particular, they showed a reduction in bleeding, odour, urinary discomfort and pain $(23,24)$. Perrone et al. reported a symptomatic response rate of $78 \%$ and they did not find differences in symptom-free survival according to previous treatments or tumor diameter (21).

In the end, with a follow-up of 6-12 months the overall survival exceeded 50\% (table II). 


\begin{tabular}{|c|c|c|c|c|}
\hline$\sum_{\substack{n \\
\vdots}}^{\pi}$ & ڤें & ' & ذ̊̊ & 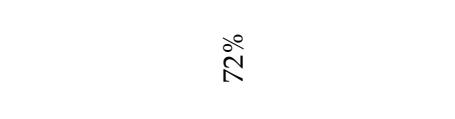 \\
\hline 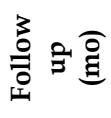 & $\begin{array}{l}n \\
\infty \\
+1 \\
+1 \\
\sigma\end{array}$ & 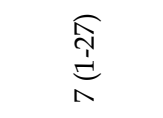 & $\approx$ & 0 \\
\hline $\bar{a}$ & 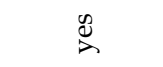 & $\stackrel{\mathscr{D}}{\mathscr{2}}$ & $\stackrel{D}{D}$ & ‡ \\
\hline 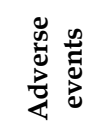 & 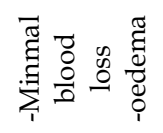 & 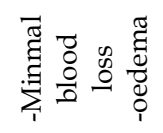 & 气̆ & 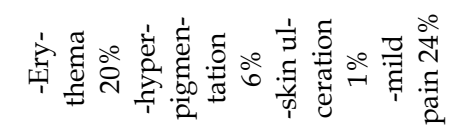 \\
\hline 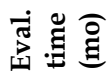 & $\neg$ & $r$ & $r$ & $N$ \\
\hline 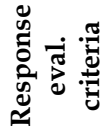 & 足 & $\underset{\substack{y \\
$\cline { 1 - 1 }$}}{5}$ & 足 & 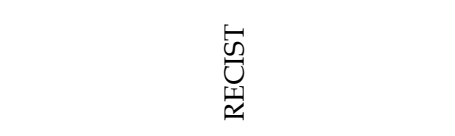 \\
\hline 尺 & 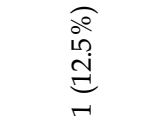 & $\frac{\widehat{o}}{\stackrel{c}{a b}}$ & 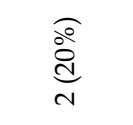 & $\begin{array}{l}\text { oे } \\
\text { in } \\
\text { மn } \\
m\end{array}$ \\
\hline 竞 & 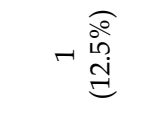 & 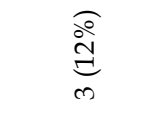 & 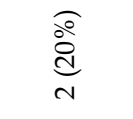 & ○ $\stackrel{\circ}{\stackrel{\circ}{\circ}}$ \\
\hline$\cong$ & 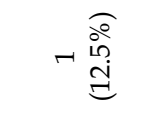 & 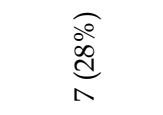 & $\underset{+}{\stackrel{\rho}{+}}$ & $\approx \stackrel{\circ}{\circ}$ \\
\hline ษั & 的 & 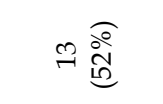 & वे & 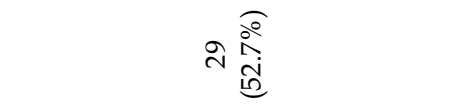 \\
\hline 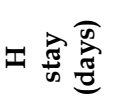 & $r$ & $r$ & ' & 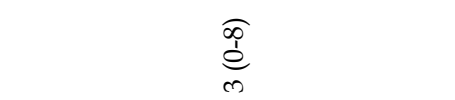 \\
\hline 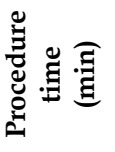 & $\begin{array}{l}\text { घี } \\
+1 \\
+1 \\
+ \\
\text { ते }\end{array}$ & $\begin{array}{l}\text { 寻 } \\
\text { वे }\end{array}$ & 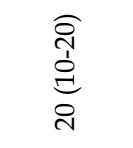 & \\
\hline 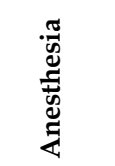 & 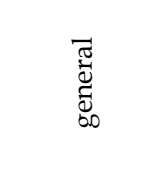 & $+\frac{0}{0}$ & ' & 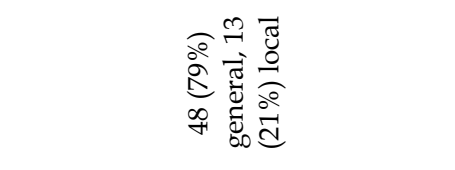 \\
\hline 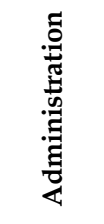 & $z$ & $\geq$ & $z$ & $\geq$ \\
\hline 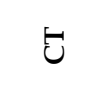 & $\sum_{\infty}$ & $\sum_{\infty}$ & $\sum_{\infty}$ & 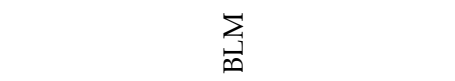 \\
\hline 苞 & 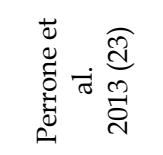 & 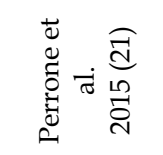 & 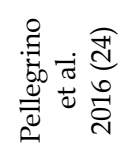 & 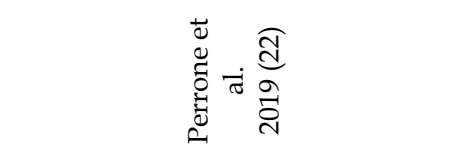 \\
\hline
\end{tabular}

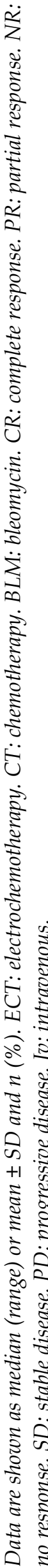



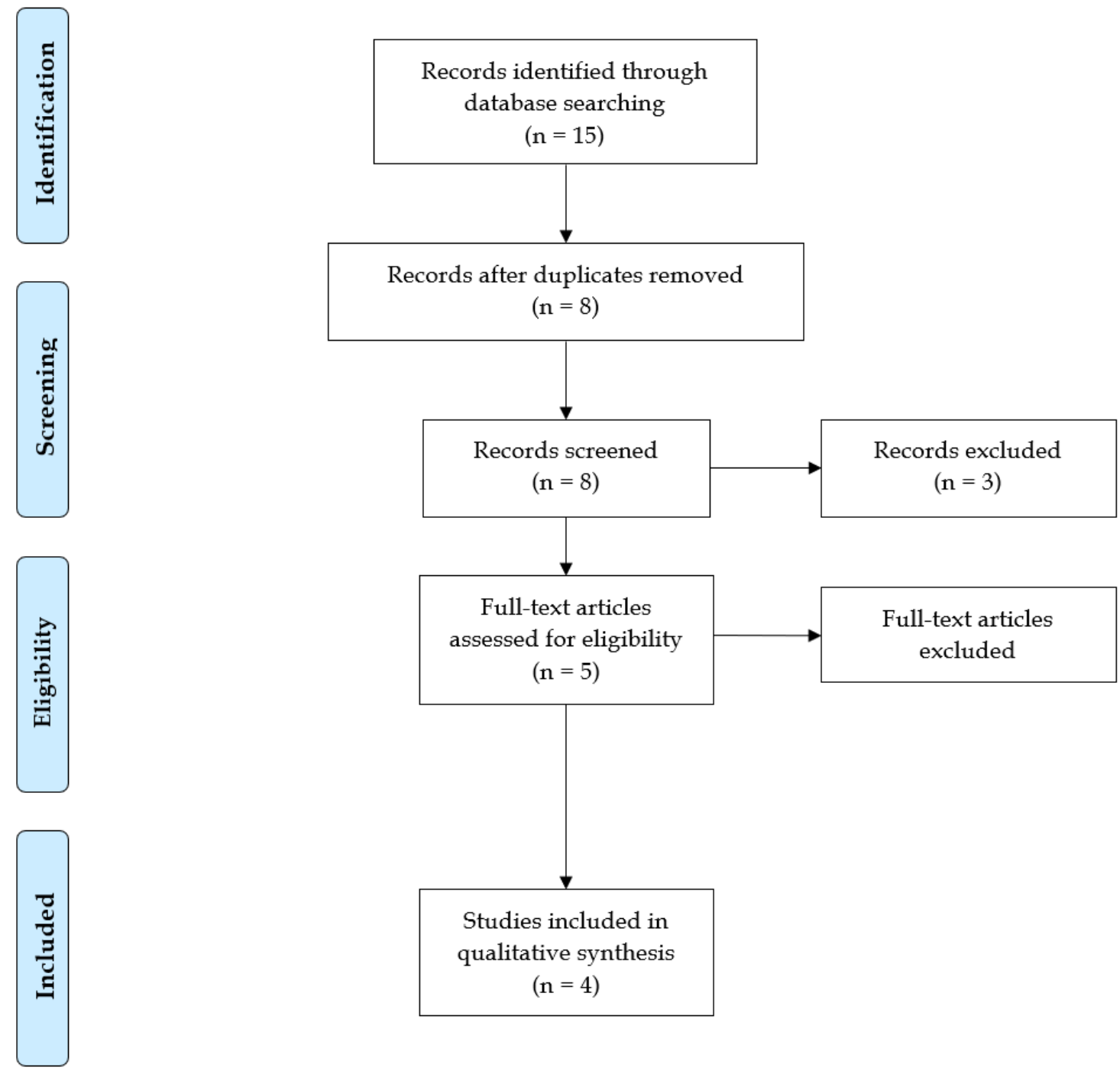

Figure 1. Flowchart for study selection and inclusion.

\section{DISCUSSION}

Modern oncology is increasingly characterized by minimally invasive therapeutic proposals (Interventional Oncology) $(25,26)$. Especially the elderly $(27,28)$ but also patients with comorbidity (29) can benefit from these types of procedures. ECT is part of this and it has demonstrated to be a valid option in the management of $\mathrm{VC}$, showing a positive clinical response and an improvement of the QoL without serious adverse events. The studies we considered in our systematic re- view were quite homogeneous. This is related to two reasons: on the one hand, the Standard Operating Procedures publication in 2006 and their update in 2018 (30) created a standardization of the procedure; on the other hand, the majority of the studies were conducted by the same institutions. Since the possibility of a duplication of the patients could not be avoided, it was not possible to add a meta-analysis, which is one of the limits of our research. Furthermore, the num- 
ber of studies on ECT in VC is very low, because of the recent application of ECT in these kind of cancers. ECT in VC showed a CR rate of $46.7 \%$ and, although the response evaluation criteria were a bit different between the studies, the CR definition is the same. In a recent meta-analysis for the evaluation of ECT in different kind of tumors (VC not included), Morley et al. reported similar results, despite a higher objective response rate $(82.2 \%)$ (31). Although some studies have reported a better response rate for tumors smaller than $3 \mathrm{~cm}$ (31) and even the Standard Operating Procedures have suggested the possibility of different chemotherapy administration according to the tumour diameter (30), none of the studies in our systematic review found differences in the response rate $(21,22)$. Furthermore, ECT response seemed not to be affected by any of the parameters considered in the studies $(21,22)$. An interesting result was the absence of influence in the response rate when a previous treatment was administered (21), whereas some studies have found that treatment-naïve tumours responded better, probably because of a worse effect of ECT after radiotherapy, due to the reduction of the blood flow because of the fibrosis (31). As regards the survival outcomes, it is difficult to get conclusions because of the lack of homogeneity among the patients. Indeed, different previous treatments or the use of co-interventions may affect the survival outcomes. However, considering that ECT was more often used as a palliative treatment or when no other treatments were available, the survival outcomes showed by our research may be promising. The most common adverse events reported by our research were local: minimal blood loss, oedema, erythema, hyperpigmentation, skin ulceration and mild pain. Morley et al. showed minimal serious adverse events, whereas the most common were mild, post-procedural nausea and dizziness (31). Although ECT is associated with a $6 \%$ incidence of G3 toxicity, this rate is similar to other skin-directed therapies (2). All the studies we considered in our systematic review agreed with the fact that ECT is associated with an improvement in QoL. In a cohort of 52 patients, Campana et al. reported positive results of ECT in melanomas on local disease-related complaints such as wound healing, bleeding or pain and on activity of daily life (32). In head and neck cancer, which is a site where maintaining physiological functions is very important, ECT showed an improvement in physical functioning, role functioning and fatigue and pain reduction (33). Further applications of ECT include extra cycles of ECT and the use of this procedure as neoadjuvant treatment. First, few data exist on additional cycles of ECT (31). In $\mathrm{VC}$, in two studies there were more than one ECT administration $(21,24)$. Perrone et al. performed a second ECT cycle in a limited number of patients (20\%) and they reported: CR $40 \%$, SD $20 \%$ and PD $40 \%$ (21). Pellegrino et al. performed even more than two cycles of ECT and no complications occurred (24). Indeed, ECT have demonstrated to be a repeatable treatment, without increasing the adverse events rate and with similar results in clinical response. Second, acceptable aesthetic and functional results are often difficult to obtain in VC and, especially, in recurrent disease and extensive reconstructions are required $(34,35)$. For this reason, ECT has been recently proposed as neo-adjuvant treatment, in order to reduce the tumor size and make the surgery less invasive and disabling. However, only one study evaluated this new application in a small group of patients with a positive objective response rate $(77.8 \%)$ (36) and further data are needed. The few data we have on extra cycles of ECT seem to suggest that it maintains its safety and efficacy. For this reason, it can be able to obtain and/or maintain the tumour clinical response through repeated cycles of ECT (31). Furthermore, since the radiotherapy and surgery are often not repeatable and the chemotherapy role is debated in $\mathrm{VC}$, according to the few but promising results of ECT as neo-adjuvant treatment, ECT may have also a theoretical role as an integrated procedure to standard surgical treatment techniques, although further specific studies are needed. Large-database using multi-centric system could help to develop predictive models (37) and decision support 
tools that could be implemented in the clinical practice for improving the multidisciplinary dicussing and for identifying the patients that may benefit by electrochemotherapy (38-40). In conclusion, ECT has demonstrated advantages in terms of reduction of hospital stay and costs. Furthermore, it is an easy, quick to perform, less invasive and repeatable procedure, which has shown a positive clinical response, a reduction in symptoms and an improvement in QoL. However, few studies are present on VC and further data are needed.

Since the survival for advanced and metastatic diseases has been, fortunately, increased, it is also important to focus our efforts on the QoL and on the local control of the disease. 


\section{REFERENCES}

(1) Miklavcic D, Corovic S, Pucihar G, Pavselj N. Importance of tumor coverage by sufficiently high local electric field for effective chemotherapy. Eur J Cancer Suppl 2006; 4:45-51.

(2) Campana LG, Miklavčič D, Bertino G, Marconato $R$, Valpione $S$, Imarisio I et al. Electrochemotherapy of superficial tumors - Current status: Basic principles, operating procedures, shared indications, and emerging applications. Semin Oncol. 2019 Apr;46(2):173-191.

(3) Sersa G, Jarm T, Kotnik T, Coer A, Podkrajsek $M$, Sentjurc M. et al. Vascular disrupting action of electroporation and electrochemotherapy with bleomycin in murine sarcoma. Br J Cancer. 2008 Jan 29;98(2):388-98.

(4) Jarm T, Cemazar M, Miklavcic D, Sersa G. Antivascular effects of electrochemotherapy: implications in treatment of bleeding metastases. Expert Rev Anticancer Ther. 2010 May;10(5):72946.

(5) Calvet CY, Famin D, André FM, Mir LM. Electrochemotherapy with bleomycin induces hallmarks of immunogenic cell death in murine colon cancer cells. Oncoimmunology. 2014 Apr 15;3: e28131.

(6) Di Gennaro P, Gerlini G, Urso C, Sestini S, Brandani $\mathrm{P}$, Pimpinelli $\mathrm{N}$ et al. CD4+FOXP3+ T regulatory cells decrease and $\mathrm{CD} 3+\mathrm{CD} 8+\mathrm{T}$ cells recruitment in TILs from melanoma metastases after electrochemotherapy. Clin Exp Metastasis. 2016 Dec;33(8):787-798.

(7) Wichtowski M, Murawa D. Electrochemotherapy in the treatment of melanoma. Contemp Oncol (Pozn). 2018;22(1):8-13.

(8) Goggins CA, Khachemoune A. The use of electrochemotherapy in combination with immunotherapy in the treatment of metastatic melanoma: a focused review. Int J Dermatol. 2019 Aug;58(8):865-870.

(9) Matthiessen LW, Keshtgar M, Curatolo P, Kunte C, Grischke EM, Odili J et al. Electrochemotherapy for Breast Cancer-Results From the INSPECT Database. Clin Breast Cancer. 2018 Oct;18(5): e909-e917.

(10) Wichtowski M, Murawa D, Czarnecki R, Piechocki J, Nowecki Z, Witkiewicz W. Electrochemotherapy in the Treatment of Breast Cancer Metastasis to the Skin and Subcutaneous Tissue - Multicenter Experience. Oncol Res Treat. 2019;42(1-2):47-51.
(11) De Virgilio A, Ralli M, Longo L, Mancini P, Attanasio G, Atturo F et al. Electrochemotherapy in head and neck cancer: A review of an emerging cancer treatment. Oncol Lett. 2018 Sep;16(3):3415-3423.

(12) Tabbaa ZM, Gonzalez J, Sznurkowski JJ, Weaver AL, Mariani A, Cliby WA. Impact of the new FIGO 2009 staging classification for vulvar cancer on prognosis and stage distribution. Gynecol Oncol. 2012 Oct;127(1):147-52.

(13) Gentileschi S, Servillo M, Garganese G, Fragomeni S, De Bonis F, Scambia G et al. Surgical therapy of vulvar cancer: how to choose the correct reconstruction? J Gynecol Oncol. 2016 Nov; 27(6): e60.

(14) Gentileschi S, Servillo M, Garganese G, Simona F, Scambia G, Salgarello M. Versatility of pedicled anterolateral thigh flap in gynecologic reconstruction after vulvar cancer extirpative surgery. Microsurgery. 2017 Sep;37(6):516-524. (15) Fanfani F, Garganese G, Fagotti A, Lorusso D, Gagliardi ML, Rossi Met al. Advanced vulvar carcinoma: is it worth operating? A perioperative management protocol for radical and reconstructive surgery. Gynecol Oncol. 2006 Nov;103 (2):467-72.

(16) Rao YJ, Chin RI, Hui C, Mutch DG, Powell MA, Schwarz JK et al. Improved survival with definitive chemoradiation compared to definitive radiation alone in squamous cell carcinoma of the vulva: A review of the National Cancer Database. Gynecol Oncol. 2017 Sep;146(3):572579.

(17) Tagliaferri L, Casà C, Macchia G, Pesce A, Garganese G, Gui B et al. The Role of Radiotherapy in Extramammary Paget Disease: A Systematic Review. Int J Gynecol Cancer. 2018 May;28( 4):829-839

(18) Edey KA, Allan E, Murdoch JB, Cooper S, Bryant A. Interventions for the treatment of Paget's disease of the vulva. Cochrane Database Syst Rev. 2019 Jun 5;6:CD009245.

(19) Moher D, Liberati A, Tetzlaff J, Altman DG; PRISMA Group. Preferred reporting items for systematic reviews and meta-analyses: the PRISMA statement. PLoS Med. 2009 Jul 21;6(7): e1000097.

(20) Mir LM, Gehl J, Sersa G, Collins CG, Garbay JR, Billard V et al. Standard operating procedures of the electrochemotherapy: Instructions for the use of bleomycin or cisplatin administered either systemically or locally and electric 
pulses delivered by the CliniporatorTM by means of invasive or non-invasive electrodes. EJC Supplements 2006;4: 14-25.

(21) Perrone AM, Cima S, Pozzati F, Frakulli R, Cammelli S, Tesei $M$ et al. Palliative electrochemotherapy in elderly patients with vulvar cancer: A phase II trial. J Surg Oncol. 2015 Oct; 112(5):529-32.

(22) Perrone AM, Galuppi A, Pirovano C, Borghese G, Covarelli P, De Terlizzi F et al. Palliative Electrochemotherapy in Vulvar Carcinoma: Preliminary Results of the ELECHTRA (Electrochemotherapy Vulvar Cancer) Multicenter Study. Cancers (Basel). 2019 May 12;11(5).

(23) Perrone AM, Galuppi A, Cima S, Pozzati F, Arcelli A, Cortesi A et al. Electrochemotherapy can be used as palliative treatment in patients with repeated loco-regional recurrence of squamous vulvar cancer: a preliminary study. Gynecol Oncol. 2013 Sep;130(3):550-3.

(24) Pellegrino A, Damiani GR, Mangioni C, Strippoli D, Loverro G, Cappello A et al. Outcomes of Bleomycin-based electrochemotherapy in patients with repeated loco-regional recurrences of vulvar cancer. Acta Oncol. 2016 May;55(5):619-24.

(25) Kovács G, Tagliaferri L, Valentini V. Is an Interventional Oncology Center an advantage in the service of cancer patients or in the education? The Gemelli Hospital and INTERACTS experience. J Contemp Brachytherapy. 2017;9: 497-498. (26) Lucatelli P, Iezzi R, De Rubeis G, Goldberg SN, Bilbao JI, Sami A et al. Immuno-oncology and interventional oncology: a winning combination. The latest scientific evidence. Eur Rev Med Pharmacol Sci. 2019 Jun;23(12):5343-5350. (27) Lancellotta V, Kovács G, Tagliaferri L, Perrucci E, Colloca G, Valentini V et al. Age Is Not a Limiting Factor in Interventional Radiotherapy (Brachytherapy) for Patients with Localized Cancer. Biomed Res Int. 2018 Jan 21; 2018: 2178469.

(28) Lancellotta V, Kovács G, Tagliaferri L, Perrucci E, Rembielak A, Stingeni L et al. The role of personalized Interventional Radiotherapy (brachytherapy) in the management of older patients with non-melanoma skin cancer. J Geriatr Oncol. 2019 May;10(3):514-517.

(29) Ferrandina G, Lucidi A, Paglia A, Corrado G, Macchia G, Tagliaferri L et al. Role of comorbidities in locally advanced cervical cancer pa- tients administered preoperative chemoradiation: impact on outcome and treatment-related complications. Eur J Surg Oncol. 201238 (3):238-44

(30) Gehl J, Sersa G, Matthiessen LW, Muir T, Soden D, Occhini A, et al. Updated standard operating procedures for electrochemotherapy of cutaneous tumours and skin metastases. Acta Oncol. 2018 Jul;57(7):874-882.

(31) Morley J, Grocott P, Purssell E, Murrells T. Electrochemotherapy for the palliative management of cutaneous metastases: A systematic review and meta-analysis. Eur J Surg Oncol. 2019 Jul 2.

(32) Campana LG, Mocellin S, Basso M, Puccetti $\mathrm{O}$, De Salvo GL, Chiarion-Sileni V et al. Bleomycin-based electrochemotherapy: clinical outcome from a single institution's experience with 52 patients. Ann Surg Oncol. 2009 Jan;16(1):1919.

(33) Bertino G, Sersa G, De Terlizzi F, Occhini A, Plaschke CC, Groselj A et al. European Research on Electrochemotherapy in Head and Neck Cancer (EURECA) project: Results of the treatment of skin cancer. Eur J Cancer. 2016 Aug; 63:41-52. (34) Weikel W, Schmidt M, Steiner E, Knapstein PG, Koelbl H. Surgical therapy of recurrent vulvar cancer. Am J Obstet Gynecol. 2006 Nov;195(5):1293-302.

(35) Rei M, Mota R, Paiva V, Duarte A, Costa J, Costa A. Recurrence of vulvar carcinoma: A multidisciplinary approach. Gynecol Oncol Rep. 2019 Jun 18; 29:38-39.

(36) Perrone AM, Galuppi A, Borghese G, Corti B, Ferioli M, Della Gatta AN et al. Electrochemotherapy pre-treatment in primary squamous vulvar cancer. Our preliminary experience. J Surg Oncol. 2018 Jun;117(8):1813-1817.

(37) Tagliaferri L, Pagliara MM, Masciocchi C, Scupola A, Azario L, Grimaldi G et al. Nomogram for predicting radiation maculopathy in patients treated with Ruthenium-106 plaque brachytherapy for uveal melanoma. J Contemp Brachytherapy. 2017 Dec;9(6):540-547

(38) Meldolesi E, Soest J, Alitto AR et al. VATE: VAlidation of high TEchnology based on large database analysis by learning machine. Colorectal Cancer 2014; 3:435-50

(39) Tagliaferri L, Budrukkar A, Lenkowicz J, Cambeiro M, Bussu F, Guinot JL, Hildebrandt G, Johansson B, Meyer JE, Niehoff P, Rovirosa A, Takácsi-Nagy Z, Boldrini L, Dinapoli N, 
Lanzotti V, Damiani A, Gatta R, Fionda B, (brachytherapy). J Contemp Brachytherapy. Lancellotta V, Soror T, Monge RM, Valentini V, 2018 Jun;10(3):260-266.

Kovács G. ENT COBRA ONTOLOGY: the co- (40) Damiani A, Masciocchi C, Boldrini L et al. variates classification system proposed by the Head \& Neck and Skin GEC-ESTRO Working Group for interdisciplinary standardized data collection in head and neck patient cohorts Preliminary data analysis in healthcare multicentric data mining: a privacy-preserving distributed approach. J E-learning Knowledge Soc. treated with interventional radiotherapy 20 